\title{
ANGIOTENSIN CONVERTING ENZYME INHIBITOR ASSOCIATED COUGH: A POPULATION-BASED CASE-CONTROL STUDY
}

\author{
L. E. VISSER, ${ }^{1}$ B. H. CH. STRICKER,${ }^{2.4 *}$ J. VAN DER VELDEN,${ }^{3}$ A. H. P. PAES ${ }^{1}$ \\ and A. BAKKER ${ }^{1}$
}

'Department of Pharmacoepidemiology \& Pharmacotherapy, Utrecht Institute of Pharmaceutical Sciences, Utrecht, ${ }^{2}$ Netherlands Centre for Monitoring of Adverse Reactions to Drugs, Rijswijk, ${ }^{3}$ Netherlands Institute for Primary Health Care, Utrecht and ${ }^{4}$ Department of Epidemiology and Biostatistics, Pharmacoepidemiology Unit, Erasmus University, Rotterdam, The Netherlands

(Received 16 June 1994; received for publication 6 December 1994)

\begin{abstract}
The objectives of this study were to determine the risk for coughing as an adverse reaction to angiotensin converting enzyme (ACE) inhibitors under everyday circumstances in a large population and to study whether this adverse effect is more common in women. A population-based case-control study was used. The study was set in the practices of 161 Dutch general practitioners (GPs), in which all consultations, morbidity, mortality, medical interventions and prescriptions were registered during 4 consecutive 3-month periods in 4 consecutive groups of 40-41 GPs. The subjects were 2436 patients with incident coughing and up to 3 controls per case were obtained (total group: 7348 controls), matched for GP and a contemporary consultation in the same 3 months. All cases and controls were 20 years or older and had no notification of respiratory infections, influenza, tuberculosis, asthma, chronic bronchitis, emphysema, congestive heart failure, sinusitis, laryngitis, haemoptysis or respiratory neoplasms during the 3-month period. The results showed that cases were 3.6 times as likely as controls to have been exposed to ACE inhibitors (95\% CI: 2.4-5.5) but after adjustment for potential confounders the odds ratio was 2.5 (95\% CI: 1.6-3.9). The crude odds ratio for males was 2.7 (95\% CI: 1.4-5.1) and for females $4.2(95 \% \mathrm{CI}$ : 2.4-7.5). The adjusted odds ratio for males was $1.8(95 \% \mathrm{CI}: 0.9-3.5)$ and for females 2.7 (95\% CI: $1.5-4.8)$. Cases were $2.7(95 \%$ CI: $1.3-5.9)$ and $3.9(95 \%$ CI: $2.3-6.5)$ times as likely as controls to have been exposed to captopril and enalapril, respectively but the adjusted odds ratio for enalapril, $2.3(95 \% \mathrm{CI}: 1.4-3.9)$ was higher than for captopril, $1.8(95 \%$ CI: $0.8-3.8)$. In conclusion we can say that the risk for coughing is increased two- to threefold among ACE inhibitor users. Although the odds ratio for females is higher than the odds ratio for males, the difference is modest.
\end{abstract}

Coughing ACE inhibitors Case-control study
Enalapril Captopril

\section{INTRODUCTION}

Since anecdotal reports began to appear in the literature in the early 1980 s, linking captopril

*All correspondence should be addressed to: Dr B. H. Ch. Stricker, Pharmacoepidemiology Unit, Department of Epidemiology and Biostatistics, Erasmus University, Dr Molewaterplein 50, $3015 \mathrm{GE}$ Rotterdam, The Netherlands. and coughing, this association has been well documented. Coughing is probably related to the pharmacological effect of the angiotensin converting enzyme (ACE) inhibitors. All ACE inhibitors have since been documented to induce this side effect. The precise mechanism is still unclear but several have been proposed, such as bronchial hyper-reactivity, increased 
cough reflex or alterations in prostaglandins, bradykinin or substance $P$. Many predisposing factors have also been reported to be related to the development of coughing, e.g. age, dose, duration of therapy, smoking status and use of $\beta$-blockers. Isolated case reports and a number of small or uncontrolled studies suggest coughing to be sex related, with women more likely to experience this side effect [1-18]. This finding has been challenged by others however $[19,20]$.

The reported frequency of coughing to ACE inhibitors varies widely in the literature, depending on the populations under study and the methodological approaches used. Two large-scale postmarketing studies with unselected patient populations yielded much lower incidence estimates than did the studies in hospital or tertiary clinics [21, 22]. In some studies, the frequency of coughing to $\mathrm{ACE}$ inhibitors was expressed as an incidence rate whereas in others cumulative incidences or prevalence estimates were used. Most studies were uncontrolled or inadequately controlled. In some follow-up studies, for instance, users of calcium-antagonists and thiazide diuretics were used as control groups $[10,12,13,23-25]$. Whether this was a good choice is questionable, because the indications for use of these drugs may differ from the reason for use of $A C E$ inhibitors. Moreover, both pharmacological groups have been suggested to be protective against ACE inhibitor-induced coughing $[26,27]$. There appears to be only one study in which along with a frequency estimate a risk estimate was also calculated [25]. This study, however, comprised a relatively small patient population.

In the light of these observations, we conducted the present population-based casecontrol study in order to obtain a risk estimate of coughing to ACE inhibitors under everyday circumstances in a large population. Second, we studied whether this adverse effect is more common in women.

\section{METHODS}

\section{Data source}

From 1 April 1987 to 1 April 1988 a National Survey of General Practice was conducted in the Netherlands. A random sample of the total population of general practitioners (GPs) in the Netherlands was taken, stratified by degree of urbanization, by region, and by dis- tance from the hospital. This resulted in the participation of 161 established GPs, covering a catchment population of approx. 335,000 persons ( $52 \%$ females). All consultations, morbidity data, prescriptions and other medical interventions were registered during 3 months in 4 consecutive groups of $40-41$ GPs. The database consisted of 168,021 consulting patients with a total of 361,018 consultations [28]. The following information contained in the National Survey has been taken into consideration for the purpose of this study: GP and patient identification codes; patient age and sex; reasons for consultation (symptoms and diagnoses) as well as concurrent diseases and data on prescribed drugs. Morbidity data were coded according to the International Classification of Primary Care (ICPC) [29] and prescription data according to the Anatomical Therapeutic Chemical (ATC) classification scheme, as recommended by the WHO [30]. At the time of data collection the only available ACE inhibitors in The Netherlands were captopril and enalapril.

\section{Design}

In order to determine the risk for coughing as an adverse reaction to ACE inhibitors, a case-control study was performed. Potential cases comprised all patients aged 20 years and older, who consulted a GP for coughing for the first time during the 3-month period (incident cases). Hence, case patients were counted once even if they had had two incident episodes of coughing during the study period. Three matched controls for every case were randomly selected from the patients who had had at least one consultation during the 3-month period with the same GP as the case and who had not reported coughing during that period. Cases and controls were excluded if any of the following diseases were registered as additional diagnosis or as underlying disease: respiratory infections; influenza; tuberculosis; asthma; chronic bronchitis; emphysema; congestive heart failure; sinusitis; laryngitis; haemoptysis or respiratory neoplasms.

\section{Data analysis}

To ensure that the period of possible exposure to the drug of interest was identical in cases and controls and to control for seasonal variations in morbidity and prescriptions, the date of first consultation for coughing of the case was used as a reference point for the determination of 
exposure in cases and controls. For each last prescription of an ACE inhibitor prior to the reference date, a treatment course was calculated from the number of prescribed tablets divided by the prescribed number of tablets per day. The length of the treatment course was multiplied with a factor of 1.1 with a minimum of 2 days and a maximum of 14 days in order to control for residual drug effects and moderate undercompliance. Subjects were defined as users if the reference date fell between the start and stop date of the estimated treatment course.

The odds ratio of exposure to ACE inhibitors among patients with coughing, compared to control patients, was calculated as a crude odds ratio with a $95 \%$ confidence interval $(95 \% \mathrm{CI})$. Only matched analyses were performed in this study. For each potential co-factor a crude exposure odds ratio was calculated. The following variables were considered as potential confounders: age; gender; number of prescriptions; number of consultations; use of nonsteroidal anti-inflammatory drugs (NSAID), $\beta$-blockers [31], thiazides [27] or calcium-antagonists [26] and smoking status. Factors that caused a change in the crude odds ratio of use of ACE inhibitors of at least $5 \%$ were included in the multivariate model, applying conditional logistic regression [32] with the EGRET statistical package [33]. Subanalyses were performed for users of captopril and enalapril, by applying the same multivariate models. Furthermore, we investigated whether this side effect was dosedependent, using the same conditional model with 3 dose levels. A separate analysis was performed with a case definition encompassing all acute respiratory infections.

\section{RESULTS}

There was a total of 1602 patients in the study base who had been prescribed an ACE inhibitor during the 3-month period. 698 had been prescribed captopril (44\%) and 904 enalapril. In this group, coughing was reported by 155 patients giving a period prevalence of $9.7 \%$. In the rest of the population (166,419 patients), coughing was registered in 10,907 patients (period prevalence: $6.6 \%$ ), which would be compatible with a risk difference of $3.1 \%$. Of the total number of patients with coughing ( $n=11,062), 2436$ were incident cases without a concurrent respiratory disease or congestive heart failure. The control group consisted of 7348 patients without concomitant respiratory illness or heart failure. Although it was not possible to find 3 controls for every case, all cases had at least 2 and the large majority of cases 3 matched controls.

A comparison of cases and controls is shown in Table 1. Several differences emerged which could explain differences in exposure frequency between cases and controls, irrespective of a real association between ACE inhibitors and coughing. Cases and controls were similar in age and there were slightly more women in the control group. Cases received significantly more prescriptions and had more consultations per person during the 3-month period than the control group. Patients without coughing were more likely to be taking $\beta$-blockers and NSAID. Numbers of prescriptions for calcium-antagonists and thiazides were not significantly different between cases and controls. Patients with coughing were more likely to be smokers. Factors were included in the model to study their effect upon the crude estimate.

Of the cases, $47(1.9 \%)$ were identified as users of ACE inhibitors, against $39(0.5 \%)$ of the controls. The results of the logistic regression analyses without (crude) and with (adjusted) controlling simultaneously for confounding variables are presented in Table 2.

Table 1. Comparison of cases and controls matched for GP

\begin{tabular}{lccc}
\hline & $\begin{array}{c}\text { Cases } \\
(n=2436)\end{array}$ & $\begin{array}{c}\text { Controls } \\
(n=7348)\end{array}$ & $\begin{array}{c}\text { Odds ratio } \\
(95 \% \text { CI }) \text { or } p \text {-value }\end{array}$ \\
\hline Mean age in years (SD) & $46.7(17.7)$ & $46.9(18.3)$ & $p=0.714$ \\
Females (\%) & $1431(59 \%)$ & $4557(62 \%)$ & $0.87(0.79-0.96)$ \\
Mean No. prescriptions & 2.14 & 1.46 & $p<0.0001$ \\
Mean No. consultations & 2.46 & 2.36 & $p=0.0016$ \\
ACE inhibitors* & $47(1.9 \%)$ & $39(0.5 \%)$ & $3.6(2.4-5.5)$ \\
NSAID* & $166(6.8 \%)$ & $737(10 \%)$ & $0.65(0.5-0.7)$ \\
$\beta$-blockers* & $89(3.7 \%)$ & $429(5.8 \%)$ & $0.6(0.5-0.7)$ \\
Thiazides* & $31(1.3 \%)$ & $91(1.2 \%)$ & $1.0(0.7-1.5)$ \\
Ca-antagonists* & $13(0.5 \%)$ & $64(0.9 \%)$ & $0.6(0.3-1.1)$ \\
Smoking & $62(2.5 \%)$ & $35(0.5 \%)$ & $5.5(3.6-8.4)$ \\
\hline
\end{tabular}

*Number of cases and controls who were exposed to the drug on the index day. 
Table 2. Crude and adjusted odds ratios (OR) for exposure to ACE inhibitors

\begin{tabular}{|c|c|c|c|c|c|c|}
\hline & \multicolumn{2}{|c|}{ Overall } & \multicolumn{2}{|c|}{ Females } & \multicolumn{2}{|c|}{ Males } \\
\hline & Crude OR & Adjusted OR & Crude OR & Adjusted OR & Crude OR & Adjusted OR \\
\hline All ACE inhibitors & $3.6(2.4-5.5)$ & $2.5(1.6-3.9)$ & $4.2(2.4-7.5)$ & $2.7(1.5-4.8)$ & $2.7(1.4-5.1)$ & $1.8(0.9-3.5)$ \\
\hline Captopril & $2.7(1.3-5.9)$ & $1.8(0.8-3.8)$ & $2.4(0.8-7.1)$ & $1.5(0.5-4.5)$ & $3.1(1.02-9.5)$ & $2.3(0.7-7.1)$ \\
\hline Enalapril & $3.9(2.3-6.5)$ & $2.3(1.4-3.9)$ & $5.3(2.6-10.8)$ & $3.4(1.7-7.0)$ & $2.4(1.1-5.4)$ & $1.7(0.7-3.9)$ \\
\hline
\end{tabular}

Exposure odds ratios with a value of unity outside the $95 \%$ confidence interval are printed in bold.

Cases were 3.6 times as likely as controls to have been exposed to ACE inhibitors $(95 \% \mathrm{CI}$ : 2.4-5.5) but after adjustment the odds ratio was 2.5 (95\% CI: $1.6-3.9)$. When results were analysed according to sex a crude odds ratio of $4.2(95 \% \mathrm{CI}: 2.4-7.5)$ was found for females which declined to 2.7 (95\% CI: 1.5-4.8) after adjustment. For males, the crude odds ratio was 2.7 (95\% CI: $1.4-5.1)$ and 1.8 (95\% CI: 0.9-3.5) after adjustment. Patients with coughing were 2.7 (95\% CI: 1.3-5.9) and 3.9 (95\% CI: 2.3-6.5) times as likcly as control patients to have been exposed to captopril and enalapril, respectively but after adjustment only the odds ratio for exposure to enalapril remained significant. Subanalyses for captopril and enalapril according to sex yielded significant crude and adjusted values for females on enalapril but not on captopril (Table 2). Although the crude exposure odds ratio was significant for captopril in males, adjusted odds ratios were nonsignificant in males for both captopril and enalapril. $\Lambda$ dose response relationship could not be observed for captopril as the crude odds ratio increased from $2.0(95 \%$ CI: $0.3-12.2)$ in those treated with doses of $25 \mathrm{mg}$ or less per day, via $2.2(95 \% \mathrm{CI}$ : 0.7-6.9) in those treated with $25-50 \mathrm{mg}$ per day, to $2.1(95 \%$ II: $0.4-12.2)$ for those patients treated with doses of more than $50 \mathrm{mg}$ per day. For enalapril, the crude odds ratio was $3.3(95 \%$ CI: $1.5-7.0)$ in those treated with a dose of $10 \mathrm{mg}$ or less per day, $5.3(95 \%$ CI: $2.2-12.7)$ in patients on $10-20 \mathrm{mg}$ per day, and $4.5(0.8-27.2)$ in those using doses of more than $20 \mathrm{mg}$ per day.

A separate analysis of the aforementioned data with a case definition including acute respiratory infections revealed similar results and is therefore not demonstrated here.

\section{DISCUSSION}

In this study, we assessed the risk for coughing in relation to treatment with ACE inhibitors in a large population under everyday circumstances. The results suggest that the risk for coughing is increased two- to threefold among patients exposed to ACE inhibitors.
Although our findings could be compatible with the previously made suggestion that coughing may occur more frequently to enalapril $[2,18,19,34,35]$, especially as the adjusted odds ratio for exposure to captopril was nonsignificant. On the other hand, there is no doubt that captopril may cause coughing and we think that if a difference between the odds ratios of exposure to enalapril and captopril exists, it is only modest. In our study, the exposure odds ratio for females was higher than that for males as the odds ratio of 2.7 and 3.4 in the adjusted analyses for all ACE inhibitors and for enalapril, respectively was not demonstrated in males. This is in line with earlier suggestions [1-18]. Why the exposure odds ratio in women is higher than in men is speculative. There are several possible explanations. First, women might visit their GP more readily and might thus be more easily recognized or diagnosed as coughing. As we controlled for the number of consultations and prescriptions, however, this explanation is not very likely. Second, women might be more sensitive to bradykinin, prostaglandins or substance $\mathrm{P}$, for instance by a difference in receptor population or sensitivity, or develop higher levels to ACE inhibitors. Third, there could be other known or unknown gender-related co-factors that might explain this difference and which were not controlled for in this study. Although the difference seems to be fairly modest, the consequences for public health may be substantial as the exposure prevalence to ACE inhibitors increases.

Although potential biases must be considered in interpreting the results of any case-control study, we think that most of these were adequately dealt with. Selection bias was not very likely to occur for two reasons. First, all consultations were registered, all cases who met the entry criteria were included in the study and selection of the control subjects was performed at random and independent of drug use. Second, during the classification of symptoms and diseases, GPs were not aware of the 
research hypothesis and no selection was made by the GP. Although it must be emphasized that the fact that not all patients will consult their GP because of coughing means that some selection inevitably occurs, it does not necessarily mean that this will bias the risk estimate. To control for this potential bias, the reference group consisted of patients who had consulted the GP in the same 3-month period. This reference group was also chosen to ensure that patients were alive and present in the catchment area and thus eligible for visits to the GPs and for filling a prescription, in order to prevent a spurious overestimation of the odds ratio. Recall bias could not have played a role as the case-control study made use of data which were already gathered before disease onset. Another type of information bias might occur, however, if GPs were more likely to diagnose coughing in users of ACE inhibitors than in other patients. Information bias could also be the result of patients who presented themselves to their GP with captopril or enalapril-associated coughing after reading the data sheet. As adverse reactions encountered during the National Survey were registered as such and because none of the patient visits for coughing were registered as adverse reactions, this seems unlikely as a substantial source of information bias. Because many GPs were not yet aware of the association between ACE inhibitors and coughing in 1987, cases of coughing may have been misclassified as acute respiratory disease, bronchitis, asthma or worsened cardiac failure. As patients with such diagnoses were also excluded from the control group, this does not necessarily jeopardize a valid estimation of the odds ratio. This assumption is endorsed by the fact that a re-analysis with a case definition consisting of coughing or acute respiratory infections did not substantially change our risk estimates. Misclassification might, however, lead to an underestimation of the incidence of respiratory adverse effects to ACE inhibitors, especially in view of the aforementioned fact that not all patients go to their GP because of coughing. Misclassification of disease in control patients might occur if they suffered from coughing, but did not present this complaint to the GP. Even if this occurred, however, it is unlikely that many controls were coughing during the short time window in which they were matched to cases. Moreover, coughing during the same period as the matched case without consulting the GP will introduce a bias towards the null hypothesis and thus lead to a conservative estimation of the odds ratio. Criteria for defining exposure should also be evaluated. Subjects were only considered as exposed if the reference date fell between the start and stop date of the last prescription which had been filled prior to the occurrence of coughing. Subjects who filled a prescription of an ACE inhibitor outside the time frame between this reference date and the beginning of the data collection, may have been misclassified as nonexposed. This nondifferential misclassification will lead to a conservative estimation of the odds ratio. Subjects may also have been misclassified as nonexposed, if they received a prescription of an ACE inhibitor from a medical specialist. As the percentages of patients under treatment of a cardiologist or a specialist in internal medicine was low and not significantly different between cases $(2.7 \%)$ and controls $(3.3 \%)(p=0.18)$, such an effect is probably negligible. An important point is the control for confounding bias which lowered our estimates of the odds ratios in the multivariate analysis. The adjusted odds ratios remained statistically significantly away from unity, except in males. It should be noted that the crude odds ratio estimates were influenced most by the adjustments for gender, number of consultations, number of prescriptions and use of NSAID and $\beta$-blockers. In our study, patients who coughed had received significantly less prescriptions of $\beta$-blockers. This is not compatible with an earlier study suggesting that $\beta$-blockers predispose to ACE inhibitorinduced coughing [31]. The meaning of the low crude odds ratio for use of NSAID and $\beta$-blockers is unclear. Some NSAID, e.g. sulindac, have been advocated in the treatment of coughing to ACE inhibitors which would be in line with a low odds ratio. A lower exposure prevalence of $\beta$-blockers in cases has also been noted by others [3]. A likely explanation is that some medical practitioners attributed coughing to chronic obstructive lung disease or asthma, conditions in which $\beta$-blockers and NSAID are contra-indicated. This would explain why the exposure prevalence in cases was lower than in controls but also that even though cases and controls with these concurrent diagnoses were excluded-some misclassification may have occurred. Although in our study smoking appeared to be related to the outcome of interest, there was no relationship with exposure to ACE inhibitors. Hence, smoking was not considered as a confounding variable in this study. 
It should be emphasized, however, that the registered number of smokers in the database was far below the expected percentage in The Netherlands. The latter is probably explained by the fact that few GPs register the smoking status of their patients. Due to the short study period of the National Survey, a duration-effect relation could not be studied. For those persons who got their first prescription before the data collection started, it was not possible to determine for how long they had been on ACE inhibitor treatment. As coughing may appear after 1 day as well as after 17 months [36], however, it may be questioned whether a duration-effect relationship would have been demonstrated. In our study, a dose-response relationship between coughing and captopril was not demonstrated, which is compatible with the literature $[2,3,9,25]$. Users of a daily dose below $10 \mathrm{mg}$ of enalapril, however, had a slightly lower risk than users of higher daily doses. There was no evidence for a protective effect of calcium-antagonists or thiazides, as has been suggested elsewhere [26, 27].

It is very difficult to compare studies of the frequency of ACE inhibitor-induced coughing in the literature. This is exemplified by the fact that the reported frequency of coughing varies from 0.5 to $39 \%$ of recipients [37]. This has several reasons. First, the risk estimate is given as a straightforward frequency in some studies but as point prevalence, period prevalence, incidence rate or cumulative incidence in others. Also, the length of the study period varies. Second, while some studies rely on spontaneous reporting, in other studies patients were specifically asked for coughing. Third, several studies comprise case series or small uncontrolled studies with retrospective review of medical records, whereas the two largest studies so far were uncontrolled. Although there were also some controlled studies, these were small and not always representative of the use of ACE inhibitors under everyday circumstances. Fourth, the setting differs in studies from patients hospitalized in tertiary clinics to data gathered in an outpatient setting. Fifth, none of the studies was controlling for the number of consultations and prescriptions per patient. For these reasons, we performed this casecontrol study in a large population under everyday circumstances. The latter is an especially important feature of the actual situation in postmarketing surveillance.

In conclusion, we demonstrated that the risk for coughing is increased two- to threefold in users of ACE inhibitors and that this increase in mainly seen in women. In view of the fact that other studies demonstrated the same under different circumstances, this gender-related effect justifies further study concerning the mechanism.

\section{REFERENCES}

1. Inman WHW. Enalapril-induced cough. Lancet 1986; 2: 1218.

2. Coulter DM, Edwards IR. Cough associated with captopril and enalapril. Br Med J 1987; 294: 1521.

3. Yeo WW, Ramsey LE. Persistent dry cough with enalapril: incidence depends on method used. $\mathbf{J}$ Hum Hypert 1990; 4: 517-520.

4. Stoller JK, Elghazawi A, Mehta AC, Vidt DG. Captopril-induced cough. Chest 1988; 93: 659-661.

5. Webb D, Benjamin N, Collier J, Robinson B. Enalapril-induced cough. Lancet 1986; 2: 1094.

6. Kaufman J, Casanova JE, Riendl P, Schlueter DP. Bronchial hyperreactivity and cough due to angiotensin-converting enzyme inhibitors. Chest 1989; 95: 544-548.

7. Hume AL, Murphy JL, Lauerman SE. Angiotensinconverting enzyme inhibitor-induced cough. Pharmacotherapy $1989 ; 9: 88-90$.

8. Morice AH, Brown MJ, Higenbottam T. Cough associated with angiotensin converting enzyme inhibition. J Cardiovasc Pharmacol 1989; 13 (Suppl 3): S59-S62.

9. McEwan JR, Choudry N, Street R, Fuller RW. Change in cough reflex after treatment with enalapril and ramipril. Br Med J 1989; 299: 13-16.

10. Yeo WW, Foster G, Ramsay LE. Prevalence of persistent cough during long-term enalapril treatment: controlled study versus nifedipine. Q J Med 1991; 80: 763-770.

11. Poole MD, Postma DS. Characterization of cough associated with angiotensin converting enzyme inhibitors. Otolaryngol Head Neck Surg 1991; 105: 714-716.

12. Yeo WW, Maclean D, Richardson PJ, Ramsey LE. Cough and enalapril: assessment by sponteanous reporting and visual analogue scale under double-blind conditions. Br J Clin Pharmacol 1991; 31: 356-359.

13. Os I, Bratland B, Dahlof B, Gisholt K, Syvertsen JO, Tretli S. Female sex as an important determinant of lisinopril-induced cough. Lancet 1992; 339: 372.

14. Strocchi E, Valtancoli G, Ambrosioni E. The incidence of cough during treatment with angiotensin converting enzyme inhibitors. J Hypert 1989; 7 (Suppl 6): S308-S309.

15. Moore $\mathbf{N}$, Noblet $\mathbf{C}$, Joannides $\mathbf{R}$, Ollagnier $\mathbf{M}$, Imbs JL, Lagier G. Cough and ACE inhibitors. Lancet 1993; 341: 61 .

16. Lefebvre J, Poirier L, Lacourciere Y. Prospective trial on captropril-related cough. Ann Pharmacother 1992; 26: $161-164$

17. Carre A, Vasmant D, Elmalem J, Thiery $P$. Tolcrability of ramipril in a multicenter study of mild-to-moderate hypertension in general practice. J Cardiovasc Pharmacol 1991; 18 (Suppl 2): S141-S143.

18. Strocchi E, Valtancoli G, Ricci C, Malini PL, Bassein L, Ambrosioni E. Postmarketing studies of subjective side effects; a case for strict methodological criteria and careful analysis of data. Pharmacol Res 1992; 25 (Suppl 1): 79-80.

19. Goldszer RC, Lilly LS, Solomon HS. Prevalence of 
cough during angiotensin converting enzyme inhibitor therapy. Am J Med 1988; 85: 887.

20. Simon SR, Black HR, Moser M, Berland WE. Cough and ACE inhibitors. Arch Intern Med 1992; 152: 1698-1700.

21. Inman WHW, Rawson NSB, Wilton LV, Pearce GL, Speirs CJ. Postmarketing Surveillance of enalapril. 1: results of prescription event-monitoring. Br Med $\mathbf{J}$ 1988; 297: 286-289.

22. Cooper WD, Sheldon D, Brown D, Kimber GR, Isitt VL, Currie WJ. Post-marketing surveillance of enalapril: experience in 11,710 hypertensive patients in general practice. J R Coll Gen Pract 1987; 37 : 346-349.

23. Os I, Bratland B, Dahlof B, Gisholt K, Syvertsen JO, Tretli S. Lisinopril or nifedipine in essential hypertension? A Norwegian multicenter study on efficacy, tolerability and quality of life in 828 patients. J Hypert 1991; 9: 1097-1104.

24. Woo J, Woo KS, Kin T, Vallence-Owen J. A singleblind, randomized, cross-over study of angiotensinconverting Enzyme Inhibitors and triamterene and hydrochlorothiazide in the treatment of mild to moderate hypertension in the elderly. Arch Intern Med 1987; 147: 1386-1389.

25. Sebastian JL, McKinney WP, Kaufman J, Young MJ. Angiotensin converting enzyme inhibitors and cough. Chest 1991; 99: 36-39.

26. Fogari R, Zoppi A, Tettamanti F, Malamani GD, Tinelli C, Salvetti A. Effects of nifedipine and indomethacin on cough induced by angtiotensin converting enzyme inhibitors: a double-blind, randomized, cross-over study. J Cardiovase Pharmacol 1992; 19: 670-673.

27. Kamei J, Kasuya Y. The effect of hydrochlorothiazide on the enhanced coughing associated with treatment with enalapril. Eur J Pharmacol 1992; 213: 137-139.

28. Foets $M$, Velden $J$ van der, Bakker DH de. Survey design. Dutch National Survey of General Practice, Utrecht, NIVEL; 1992.

29. Lamberts $\mathbf{H}$, Woods $\mathbf{M}$. International Classification of Primary Care. Oxford: Oxford University Press; 1987.

30. Anonymous. Anatomical Therapeutic Chemical (ATC) Index: Including Defined Daily Doses (DDD) for Plain Substances. Oslo: World Health Organization; 1987.

31. Puolijoki HJ, Nieminen MM, Siitonen LO, Lahdensuo AH, Reinikainen PM. Is a simultaneous beta-blocker therapy a risk factor for enalapril-induced cough? Respiration 1989; 55: 127-128.

32. Kleinbaum DG, Kupper LL, Muller KE. Applied Regression Analysis and Other Multivariate Methods. Boston: PWS-Kent Publishing Company; 1988.

33. Egret. Statistics and Epidemiology Research Corporation, Seattle, WA.

34. Town GI, Hallwright GP, Maling TJB, O’Donnell TV. Angiotensin converting enzyme inhibitors and cough. N Z Med J 1987; 100: 161-163.

35. Croog SH, Levine S, Testa Ma, et al. The effects of antihypertensive therapy on the quality of life. N Engl J Med 1986; 314: 1657-1664.

36. Just PM. The positive association of cough with angiotensin-converting enzyme inhibitors. Pharmacotherapy $1989 ; 9: 82-87$.

37. Israili $\mathbf{Z H}$, Hall WD. Cough and angioneurotic edema associated with angiotensin-converting enzyme inhibitor therapy. A review of the literature and pathophysiology. Ann Intern Med 1992; 117: 234-242.

38. Hood S, Nicholls MG, Gilchrist NI. Cough with angiotensin converting enzyme inhibitors. $N \mathbf{Z}$ Med J 1987; 100: 6-7.

39. Gibson GR. Enalapril-induced cough. Arch Intern Med 1989; 149: 2701-2703.

40. Lunde $H$, Hedner Th, Samuelsson $O$, Lotvall J, Andren L, Lindholm L, Wiholm B. Dyspnoea, asthma and bronchospasm in relation to treatment with angiotensin converting enzyme inhibitors. Br Med $\mathbf{J}$ 1994; 308: 18-21.

41. Adams JW, Hard PB. Adverse effects of ACE inhibitors. Ann Intern Med 1993; 118: 314-315.

42. Reisin L, Schneeweiss A. Complete spontaneous remission of cough induced by ACE inhibitors during chronic therapy in hypertensive patients. J Hum Hypert 1992; 6: 333-335.

43. Fuller RW. Cough associated with angiotensin converting enzyme inhibitors. J Hum Hypert 1989; 3 (Suppl 1): 159-161.

44. Berkin KE, Ball SG. Cough and angiotensin converting enzyme inhibition. Br Med J 1988; 296: 1279.

45. Sesoko S, Kaneko Y. Cough associated with the use of captopril. Arch Intern Med 1985; 145: 1524.

46. Hallwright GP, Maling TB, Town GI. Enalapril and cough: case report. N Z Med J 1986; 99: 66-67.

47. Semple PF, Herd GW. Cough and wheeze caused by inhibitors of angiotensin converting enzyme. $\mathbf{N}$ Engl $\mathbf{J}$ Med 1986; 314: 61 . 